\title{
Party, ethnicity, or region? Determinants of informal political exchange in the parliament of Ghana
}

\author{
Anja Osei \\ University of Konstanz, Germany \\ Thomas Malang \\ University of Konstanz, Germany
}

\begin{abstract}
This article analyzes the patterns of informal political exchange between Ghanaian parliamentarians. Whereas research on Western parliaments identifies the party dimension as the strongest predictor for explaining exchange patterns, we develop three possible theoretical explanations for non-Western legislatures. We try to explain informal political exchange by shared ideology (party), solidarity (ethnicity), or same material interests (region). We test our claims by a novel data set based on a survey with almost all members of the current Ghanaian legislature. We analyze the exchange network using exponential random graph models. Our results suggest that regional origin, as compared to party attachment and ethnicity, is the superior predictor for informal political exchange between parliamentarians.
\end{abstract}

\section{Keywords}

Ghana, informal exchange, MPs, non-Western parliaments, social network analysis

\section{Introduction}

"We disagree on politics, but we eat together," this is how a parliamentarian described the atmosphere in the Ghanaian legislature. ${ }^{1}$ Indeed, when one visits the National Assembly before or after a parliamentary session, one sees groups of deputies standing together chitchatting with each other in the entrance hall, the parlors, or the cafeteria. Obviously, a lot of informal exchange is going on: by discussing the current affairs, Members of Parliament (MPs) are able to obtain important information, exchange views, and even agree on common political strategies vis-à-vis the upcoming decisions.

Such informal political exchange is a routine behavior of parliamentarians. However, there is not a single empirical study that examines the determinants of informal exchange in African parliaments. This lack of empirical knowledge must be placed in the context of a general research gap: African parliaments are one of the most seriously underresearched areas in political science today (AzevedoHarman, 2012; Barkan, 2009). Furthermore, data on the core functions of parliaments, like their legislative voting behavior or their communication through speeches, is not available for most African chambers. Even in a comparatively well-studied country like Ghana, no data exist on the voting behavior of MPs. Neither does the Parliament of Ghana keep records on roll call votes, nor are there publicly available data on the activities of the parliamentary committees.

This article contributes to the existing literature by analyzing informal political exchange in an African country for the first time. We identify three mechanisms that could explain informal political exchange: similarity in party attachment; similarity in ethnicity; and regional similarity.

Given the limited availability of data on African parliaments, we build our analysis on a novel data set that was collected in face-to-face interviews in the Parliament of Ghana in 2013. The survey, which achieved a response rate of $92 \%$, contains two types of data: attribute data on core

Paper submitted 2 October 2015; accepted for publication 8 July 2016

Corresponding author:

Anja Osei, University of Konstanz, Pf. 90, Konstanz, 78457, Germany.

Email: anja.osei@uni-konstanz.de 
personal characteristics such as gender, age, ethnic group, and so on, and relational data on discussion networks within the parliament. To test our claims about informal political behavior, we apply methods of social network analysis, especially exponential random graph models (ERGMs). Our results suggest that regional origin, as compared to party attachment and ethnicity, is the superior predictor for informal political exchange between parliamentarians.

The article proceeds as follows: The section 'Theory' lays out our theoretical assumptions, from which we deduct our hypotheses. The section 'Data and method' describes our method and the process of data collection, and the section 'Analysis and results' is devoted to the empirical analysis. The section 'Conclusion' draws some conclusions from our findings.

\section{Theory}

\section{Parliamentary cleavages}

Parliaments are important arenas of decision-making. Besides the formal procedures, however, parliamentarians also engage in informal interactions. In the view of elite theory, these informal interactions are a precondition for democracy. Dense networks of personal communication, friendship, and influence are believed to build mutual trust and common values (Putnam, 1976: 112). Thus, elites might begin to share a basic consensus on the rules of the game - not necessarily on single issues - which allows them to find compromises without resorting to violent or other unconstitutional means (ibid.: 126; Higley and Burton, 2006). In short, unified elites govern more effectively (Aron, 1950). ${ }^{2}$

While it is generally accepted that a certain degree of elite integration and informal cooperation is desirable and even necessary for the functioning of a political system, an important question is which factors drive this cooperation. Cooperation across political and social divides may indeed create favorable conditions for a functioning democracy, but exchanges that stay within political divides may further enhance existing cleavages. This is not only true for political divides along party lines but also for other potentially important political identities such as ethnic group, origin, or religion.

Our general theoretical approach is to use sociological network theory to explain patterns of informal political elite coordination in the Ghanaian parliament. McClurg and Lazer (2014) argue in an overview article that social network analysis has a long-standing foothold in the study of legislative organization. There are two important dimensions of how social network analysis can contribute to our understanding of parliamentary behavior. First, most studies see legislatures not only as an institution that organizes political elites but also as social space that offers opportunities to build social relationships based on common interests emerging out of complex combinations of "partisan, ideological, institutional, geographic, demographic, and personal affiliations" (Fowler, 2006: 457). Second, one of the most basic and important relations which these studies build on is the access and exchange of information as "the most important precondition for effectively influencing governments" (Auel and Benz, 2005: 386). For the purpose of this article, we concentrate on partisan, ethnic, and regional affiliations and their effect on the political information exchange in the parliament: MPs contact their fellow MPs based on personal attributes to attain knowledge on specific issues and to exchange views on upcoming political decisions.

In order to deduce hypotheses that are based on the contemporary state of knowledge in the field of African politics, the next section will introduce the basic features of Ghana's party system.

\section{The party system in Ghana}

Like most other African countries, Ghana's society is multiethnic. The Akan are the largest group with $47.5 \%$ of the population, followed by the Mole-Dagbani group (16.6\%), the Ewe (13.9\%), and the Ga-Adangbe (7.4\%). ${ }^{3}$ There are also many smaller groups like the Guan, the Grusi, or the Gurma. None of the 10 regions of modern Ghana is actually ethnically homogeneous, but it can roughly be said that the Ewe are the majority in the Volta Region, whereas Ashanti, Brong-Ahafo, Central, Eastern, and Western are dominated by ethnic Akan. The three northern regions are populated by many different ethnic and language groups, the largest being the Mole-Dagbani group, but a political identity of the "Northerner" has developed over time. The homeland of the Ga-Adangbe is Greater Accra, but because of the cosmopolitan character of Accra as the capital of Ghana, they constitute only a minority there today. All parties that exist today came into being in 1992, when the former military ruler Jerry John Rawlings announced the return to multiparty politics. Rawlings transformed his Provisional National Defence Council which had ruled the country autocratically since 1981 , into a political party, the National Democratic Congress (NDC). Besides some smaller opposition parties, the NPP (New Patriotic Party) emerged as the major opposition party. The NPP is an offshoot of the so-called Busia-Danquah tradition, a longstanding political tradition in Ghana with strong roots especially in the Ashanti and Eastern regions (for more on this, see Jonah, 1998).

In 2012 - our observed legislative period - the NDC emerged as the winner of the general elections.

While voting patterns and elections in Ghana have been extensively analyzed elsewhere (Fridy, 2007; Whitfield, 2009), two things are important for this article. On the one hand, it can be seen that the two major parties NPP and 
NDC are clearly dominating the political scene. Especially in comparison to other African countries, Ghana's parties appear to be relatively well institutionalized (Basedau and Stroh, 2008: 19; Osei, 2012). Secondly, ethnicity has a certain influence on party politics and voting, even if none of the parties is actually an ethnic party. Ethnicity, however, interacts strongly with regionalized voting patterns. A characteristic pattern in the 2000 and 2004 elections was the Akan/non-Akan divide in voting (see also BoafoArthur, 2006: 4). The NPP drew its main support from the regions with an Akan majority, while the NDC had a strong support base in the Volta Region, in Upper East, Upper West, and the Northern Region, where the majority of inhabitants are non-Akan.

As Table A1 in Appendix 1 shows, voting patterns and parliamentary representation of voters in Ghana are influenced by a complex interplay of ethnicity, regionalism, and party affiliation. This can be expected to have an impact on the interaction between MPs: they may form ties along a common ethnic or regional identity, but they might also interact strongly with their co-partisans.

\section{Hypotheses}

Homophily is the principle that a contact between similar actors occurs at a higher rate than among dissimilar actors (McPherson et al., 2001). Deduced from this "quasi-law" of tie formation in social networks, we assume for our case that the likelihood of discussing political matters is higher when MPs share a common attribute. This attribute should influence either their policy preferences or their willingness to cooperate and deliver valuable information. We theorize three dimensions of similarity that are discussed in research on African politics, namely partisanship, ethnicity, and regional origin.

Research on Western parliaments has emphasized political parties as the single important factor for influencing MPs' formal and informal behavior. More generally, Müller (2000: 309) states that political parties are "the central mechanism to make the constitutional chain of political delegation and accountability work in practice." Party groups unite individual MPs behind ideologies and policies, organize the agenda of the parliament, and determine its procedure (Kopecký, 1996: 66). In a recent survey among German MPs, almost $93 \%$ indicate that they contact MPs from the same party to inform themselves about European Union policies, whereas $58 \%$ never ask MPs from other parties (Wonka and Rittberger, 2014: 635). ${ }^{4}$ While the importance of parties cannot be denied, empirical research on parliamentarians presents a more nuanced picture. In a study of German MPs, Best (2010: 106) finds that $65 \%$ of the respondents somehow feel a degree of "togetherness" with MPs of other parties, 35\% answered that they had nothing in common with them. At the same time, German political elites are highly integrated, and only a minority of $13 \%$ reported that they had no informal contacts with members of other parliamentary parties (ibid.: 110).

If we assume that members of the same political party share a common ideology and attitudes, we should also see an increase in the likelihood of contacts between them. This could be either because of the perception that party peers generally have credible and useful information. It could also be that "discussing political matters" is a sort of streamlining the preferences of the party leaders to all MPs of that party. While studies on the United States have assigned a high importance to party membership and political positions for the formation of ties between legislators (Fowler, 2006), party ideologies are generally weakly developed in Africa. Ghana might be an exceptional case here, because the two major parties NPP and NDC expose a certain degree of issue orientation and ideological differentiation. In addition, the fact that more than $80 \%$ of the Ghanaian voters have stable party preferences (Lindberg and Morrison, 2005) leads to the assumption that parties are important ideological units of political action. Empirical studies have, however, come to contradicting conclusions about the impact of party programs on voting decisions (Obeng-Odoom, 2013). Yet, as Obeng-Odoom (2013: 76) argues, most of these studies focus voters' attitudes and not the behavior of the parties themselves. The few studies that actually take the supply side into account (Elischer, 2012; Obeng-Odoom, 2013; Osei, 2012; Rauschenbach, 2015) tend to attach greater importance to party manifestos and ideological traditions as means of internal cohesion and external differentiation. The literature usually emphasizes the existence of entrenched political traditions that can be traced back to post- and even preindependence political conflicts. Thus, the NPP presents itself as a center-right party which embraces liberalism and free market policies, whereas the NDC takes a more socialdemocratic and pro-poor stance (Elischer, 2012; Jonah, 1998; Obeng-Odoom 2013; Osei, 2012). Radical leftwing Nkrumahism, ${ }^{5}$ the third important ideological strand, is today largely marginalized but lives on only in a few small parties. Although post-independence party development was repeatedly interrupted by military coups, every new republic reproduced exactly these same political cleavages. Even if today's parties appear to be more pragmatic in their policy decisions (Obeng-Odoom, 2013), we argue that each party possesses a set of shared beliefs that provides a platform for internal cohesion and intermingling. We therefore hypothesize that:

H1: Members of the same party are more likely to discuss political matters with each other (party homophily).

Similarity based on ethnicity is the second explanatory factor for informal political exchange. In Africa, political parties and parliaments are considered as weakly 
institutionalized. Against this background, the emerging literature on voting behavior in Africa has extensively discussed the impact of ethnicity on party politics. Some authors see voting in multiethnic countries as little more than an ethnic census (Horowitz, 1985), but more recent publications argue that ethnicity "does not explain party preference as a whole" (Basedau et al., 2011: 462). Most parties are indeed multiethnic, and the salience of ethnicity for party politics varies widely across the continent. Still, the question of ethnicity is important for the understanding of informal cooperation in African parliaments, because ethnic groups provide a mechanism of solidarity which is based on similarity in language, culture, and beliefs.

In Ghana, ethnic tensions have occurred occasionally between the Akan and the Ewe group. Especially, the NPP has sometimes been accused of being an "Akan party." Belonging to the same ethnic group might therefore enhance the level of trust to otherwise unknown individuals. In relation to party politics, two mechanisms can be distinguished: ethnicity as a "shortcut" in the coordination between voters and parties, and ethnicity as a factor for internal party conflict and factionalism. Regarding the first mechanism, authors like Posner (2005: 91) have shown that ethnicity is assumed to convey information about the likely patterns of patronage distribution. Similarly, Mozaffar and Scarritt (2005: 400) hold that ethnicity provides a certain predictability in Africa's young and often fluid multiparty systems which can have a high impact on voting decisions especially when little other information about the candidates is available (Conroy-Krutz, 2013: 348). At the same time, Ghana's parties are to varying degrees internally fragmented along ethnic lines (Bob-Milliar, 2012). This is very clear in the case of the NPP where power struggles have often been fought between the Akan and other ethnic groups, but also between Akan subgroups (ibid.). Factionalism in the NDC is more dynamic and harder to grasp, but a recent study has shown that internal networks of power and influence also tend to be built around ethnic identities (Osei, 2016). Ethnicity plays an important role in the allocation of party positions and therefore provides a strong incentive for MPs to seek exchange relationships with their ethnic peers. Factionalism becomes visible mostly in concrete situations, for example, the nomination of presidential candidates. It is yet very likely that the conflicts that usually arise at this stage are the result of perpetuated interaction patterns rather than spontaneous ethnic solidarities: they only bring to light the informal networks that have been built up over longer periods of time. These arguments are especially valid in the context of the Parliament of Ghana, where half of the ministers are chosen from the ranks of the MPs. Under the general assumption that most MPs are ambitious (Young, 2014), they will seek to build up personal networks that further their future advancement. Given the preexisting patterns of ethnic factionalism in conjunction with the cultural proximity that ethnic provides, we assume that a large amount of political exchange takes place along the ethnic dimension based on the mechanism of solidarity:

H2: MPs with the same ethnicity are more likely to discuss political matters with each other (ethnic homophily).

Furthermore, originating from the same Ghanaian region increases the probability of common policy problems. As many authors have noted, political representatives are expected to embody their community and to deliver material benefits. Lindberg (2010: 3) observes that the role of the MP as "father/mother" of the community puts a lot of pressure on the deputies to "speak on the floor of the House as much as they can and bring knowledge of their constituency and their people's needs to bear on issues under debate." He also finds that most MPs spend a lot of energy in lobbying the government to allocate resource such as schools, roads, or hospitals in his or her particular constituency (Lindberg, 2009).

The explanation for regional ties is to be distinguished from ethnic formation, because the theorized mechanism is different, and regions are not necessarily ethnically homogeneous. Regionalism is a strong feature of Ghanaian politics. Like in many other African countries, the colonial infrastructure laid the foundation for an uneven regional development. The Akan regions are generally better off than the non-Akan regions. The political identity of the Northerner, for example, comprises all ethnic groups inhabiting the territory of the three northern regions. The political salience of the South-North divide is confirmed by the fact that the Ghanaian parties are seeking a balance in the nomination of presidential candidates and their running mates and also of ministerial nominations. MPs from the same region might have common interests. They might, for example, lobby for development projects such as roads, schools, and hospitals, to be channeled to their regions. The importance that MPs attach to the regional coordination of resource allocation and development programs must be understood in the context of local government sector reforms that the Ghanaian state has undertaken over the past decades. Since the adoption of the Local Government Act in 1993, the local administration lies in the hand of District Assemblies whose tasks include the formulation and execution of development plans. Among other elected representatives, the MPs of the constituencies located in the district are members of the respective District Assembly. At the regional level, the activities of the assemblies are coordinated and overseen by a Regional Coordinating Council which is headed by the Regional Minister. As a result, MPs do not only have to work together in the District Assemblies but can also lobby the Regional Minister-who is in many cases also a member of parliament - for an equitable distribution of development projects within the 
region. ${ }^{6}$ To ensure a fair distribution of resources between the regions, MPs have formed regional caucuses. These have emerged out of an ad hoc group of MPs from the Northern Region in 1997 and have since then become a common feature in the Parliament of Ghana (OwusuMensah, 2014: 257). Although regional caucuses have remained informal institutions without clear structures, they tend to pursue common goals such as disseminating information and lobbying the executive (ibid.).

Taken together, these structures provide a number of distributional incentives for MPs to link up with fellows from the same region:

H3: MPs from the same region are more likely to discuss political matters with each other (regional homophily).

Whereas we are specifically interested in the three competing explanations of group homophily, we are estimating a complete network including individual properties of MPs that should also have an influence on informal political exchange. We label these factors controls although they might attract some interest on their own.

At a very general level, we expect to find a large number of reciprocated connections. In other words, incoming ties increase the likelihood for an outgoing tie to the same actor. This is consistent with the findings of (Fowler, 2006: 462). Our first control hypothesis therefore is:

C1: Being the target of political discussion increases the likelihood of choosing the same MP as important discussion partner (reciprocity).

Most politically relevant information is generated in ministries. Especially in Ghana, where half of the ministers are chosen from the ranks of the parliamentarians, a network of contacts and supporters within the party is a necessary asset. For parliamentarians, political discussions with ministers are important to gain privileged access to information, which, in turn, might help them to advance within the party hierarchy. Our second control hypothesis shall therefore be:

C2: Being part of the government/having held a position as a minister in one of the previous governments increases the likelihood of being chosen as political discussion partner (minister).

This reasoning might apply not only to ministers but also to the most successful MPs. If we take the election result as a measure of success, other MPs might seek to contact very successful MPs because they possess valuable information on how to convince voters and win elections by a wide margin. Generally, people with a higher status are expected to receive more friendly connections because their popularity breeds followers. We expect that they will receive an above average number of incoming ties:
C3: The better the election result, the more often an MP is chosen by others as a discussion partner (result).

In all political systems, status or prestige might be correlated with age: Older MPs are believed to be more experienced. This is even truer for African cases, where gerontocratic considerations are believed to be at work to much greater extent (see, e.g. the volume edited by Aguilar, 2007). We therefore hypothesize:

C4: The older an MP, the more often he is chosen as a discussion partner (age).

Other control variables at the individual level comprise the gender of MPs as well as the number of legislative periods that the MP has spent in the parliament.

\section{Data and method}

After having compiled a list of testable hypotheses, we test them with a unique data set on informal political relationships in the Ghanaian parliament. This section will introduce the operationalization of the variables and describe the data collection process.

\section{General data collection process}

There are 275 deputies in the current Ghanaian parliament. Of these, 148 belong to the NDC, 123 to the NPP (New Patriotic Party), and 1 to the People's National Convention. In addition, there are three independent MPs.

Two hundred and fifty-three (92\%) MPs took part in the survey. This exceptional response rate eliminates some pitfalls of interviews with MPs from the beginning (Bailer, 2014). We obtained this - for Western parliaments almost unachievable - response rate by close collaboration with the Center for Democratic Governance Ghana (CDD). Data collection took place in between June and August 2013. The CDD's excellent contacts in the parliament of Ghana proved an invaluable asset. A number of steps were taken to ensure the collaboration of the MPs. First of all, the parliamentary leadership was formally informed about the objectives of the project. In addition, we sent a letter to each MP stating that all data would be used for scientific purposes only and that no sensitive information connected to individual names would be published. Ten interviewers were then recruited for the fieldwork; four of them were employees of the Research Department of Parliament, which kindly supported our efforts (for more on data collection see also, Osei, 2015).

MPs were interviewed using a standardized questionnaire. We collected two types of data: attribute data (biographical data, career patterns, and values) and relational data on the interaction patterns between the MPs. There were only three MPs (one NDC, one NPP, and one independent) who did not take part in the survey and who were 
not nominated by any other person. We excluded these MPs from the analysis. One additional person, the Speaker of Parliament, had to be included due to the number of nominations, although he is not an MP in the strict sense. Finally, this yields a network with data on 273 MPs. This complete set of actors impedes problems of sampling or boundary specification. We can make inference about the whole parliament with some confidence. Since the network to be modeled is directed and we concentrate on edges as the unit of analysis, there are $n \times n-n=74256$ possible links as observations in the network.

\section{Dependent variable}

Studies that collect relational data typically use name generators which elicit the alters in ego's personal network (Bailey and Marsden, 1999). The data collection process described in this article is without precedent and included a relatively high risk because there has been almost no experience with name generators in standardized elite surveys in Africa. To avoid cultural misunderstandings or widespread nonresponse due to narrowly or misleadingly formulated questions, it was decided to ask only a single, simple name generator question which is a modified version of a question which was first used in the General Social Survey and has since been a standard tool for obtaining network information. ${ }^{7}$ The concrete wording of the question in the survey reads as follows:

Looking back over the last six months, who are the people in the Parliament of Ghana with whom you have discussed important political decisions? Please give me their names.

The question has two advantages: first, it is sufficiently general to be understandable across various cultural contexts, and second, it focuses explicitly on the dimension of political exchange by asking for discussion networks on political decisions in a specific arena, the Parliament of Ghana. An alternative would have been to ask about exchange relations with regard to specific events or policy decisions (for an elite network study of this kind, see Higley et al., 1991). Since the Parliament of Ghana does not keep any written record on agendas or roll call votes, this was, however, not feasible due to a lack of reliable information. The high response rate of the survey obviously justifies our strategy. More work has nevertheless to been done on the cultural dimensions of name generator usage in Africa. The reaction of some MPs in the pretest and in a few qualitative interviews at least hints at an understanding of "discussing political decisions" as a form of rather intense social contact, in many cases even amounting to friendship (see Osei, 2015).

Although we would assume that "discussing important political decisions" is an undirected process, the survey item contains information about the requester and the target of the request, for example, it is directed. The original question contains an ordinal variable measuring no contact, weak contact, and strong contact. We decided for the sake of parsimony to dichotomize the relation, either a respondent indicated that there was no political contact (coded 0 ) or there was a political discussion (coded 1). A survey artifact is that respondents were given five lines to name their main contacts. As an effect, most MPs assigned five main contacts. We controlled for that design issue by setting a maximum outdegree of five in the ERGMs.

\section{Independent variables}

The independent variables were collected by a set of biographical questions, containing, for example, gender, age, ethnic group, regional origin, and so on. For our main homophily tests, we use the party of the respective MP, her home region based on the electoral district, and information about her ethnicity. The article therefore refers to the concept of "politically relevant groups" (Wucherpfennig et al., 2011) and codes ethnic groups along the lines of the Ethnic Power Relations Dataset (Cederman et al., 2010). Thus, the Akan, ${ }^{8}$ Ewe, and Ga were included in the analysis as individual groups, whereas the Gurma, Grusi, and MoleDagbani were merged into the category Northerners. The Guan cannot be incorporated into one of the other categories and therefore constitute a group of their own.

The main effects on the attribute level were captured by the following operationalization: Minister measures if an MP is or was part of the government (Minister $=1$ ) or not. Age is introduced as a continuous variable. Gender measures either a female $($ Gender $=1)$ or a male MP. The maturity of an MP is captured by his terms in office. His success is measured by the percentage of votes in the last election in his district.

\section{Methodology and model specification}

The purpose of this article is twofold. On the one hand, a statistical network model will be employed to test the main factors for tie formation, especially the difference between party, region, and ethnicity as driving factors for homophilic behavior. On the other hand, the goal is to model the informal behavior of MPs as adequately as possible. We assume (and empirically test later) that our network shows complex dependencies between ties, resulting in matrix autocorrelation. In other words, the error terms in a simple ordinary least square (OLS) regression would be correlated across observations, standard errors would be too small, and $p$ values too optimistic. We therefore model the dependencies directly as a social network and draw on the family of ERGMs, or $p^{*}$ models, described by Robins et al. (2007) and implemented as well as described in the statnet package (Handcock et al., 2008; Hunter et al., 2008) for the statistical computing environment (statistical programm) $R$. 
Table I. ERGM of informal political exchange.

\begin{tabular}{|c|c|c|c|c|c|}
\hline & Individual & Party & Ethnicity & Region & Reduced model \\
\hline Edges & $-7.49(6.36)$ & $-8.17(5.88)$ & $-9.61(6.63)$ & $-8.03(6.49)$ & $-2.46 * * *(0.16)$ \\
\hline Reciprocity & $1.21 * * *(0.18)$ & $1.19 * * *(0.19)$ & $1.14 * * *(0.17)$ & 1.19 *** $(0.20)$ & $1.14 * * *(0.17)$ \\
\hline Result & $0.00 *(0.00)$ & $0.00(0.00)$ & $0.00(0.00)$ & $0.00(0.00)$ & \\
\hline Terms & $-0.02(0.02)$ & $-0.01(0.02)$ & $0.00(0.03)$ & $-0.01(0.02)$ & \\
\hline Age & $0.00(0.00)$ & $0.00(0.00)$ & $0.00(0.00)$ & $0.00(0.00)$ & \\
\hline Minister & $0.36 * * *(0.07)$ & $0.36 * * *(0.05)$ & $0.37 * * *(0.06)$ & $0.36 * * *(0.06)$ & $0.37 * * *(0.06)$ \\
\hline Gender & $0.00(0.08)$ & $0.02(0.08)$ & $0.00(0.08)$ & $0.02(0.07)$ & \\
\hline Party homophily & & $0.00(0.07)$ & & & \\
\hline Ethnic homophily & & & $0.15 * *(0.07)$ & & $0.11(0.08)$ \\
\hline Regional homophily & & & & $0.24^{* * *}(0.09)$ & $0.20 * *(0.10)$ \\
\hline GWESP $=0$ & I.3I*** $(0.07)$ & $1.3 \mathrm{I} * * *(0.08)$ & I.3I $* * *(0.07)$ & I.3I $* * * *(0.07)$ & I.3I*** (0.07) \\
\hline GWDSP $=0$ & $-0.22 * * *(0.02)$ & $-0.22 * * *(0.02)$ & $-0.22 * * *(0.02)$ & $-0.22 * * *(0.02)$ & $-0.22 * * *(0.02)$ \\
\hline $\mathrm{AIC}$ & -1790.22 & $-|783.6|$ & -1790.73 & -1786.37 & -1789.04 \\
\hline $\mathrm{BIC}$ & -1707.28 & -1691.46 & -1698.57 & $-|694.2|$ & -1724.53 \\
\hline Log likelihood & 904.11 & 901.81 & 905.36 & 903.18 & 901.52 \\
\hline
\end{tabular}

Note: ERGM: exponential random graph model; GWESP: geometrically weighted edgewise shared partner distribution; GWDSP: geometrically weighted dyad-wise shared partner distribution.

$* * * p<0.01$; **p $<0.05$; *p $<0.1$.

ERGMs are an attempt at modeling the tie structure of a whole network in a bottom-up fashion by describing the network in terms of endogenous structural properties like cycles, clustering or density, and covariates, which can take the form of nodal attributes (e.g. actor type) and edge covariates (i.e. other relations). ${ }^{9}$

The model is fitted via Markov chain Monte Carlo maximum likelihood estimation. The estimated coefficients can be interpreted like in a logit regression model. The dependent variable is the log odds of establishing a network tie. Coefficients are interpreted as log odds ratios conditional on the rest of the network.

\section{Analysis and results}

Table 1 shows the estimation results for five models. Model 1 contains the main effects only. The next three models test the different homophily specifications. We prefer the strategy of introducing the homophily effects separately because especially the variables "region" and "ethnicity" are correlated. Therefore, unbiased estimates are questionable if we would introduce them together. However, model 5 is a robustness test which contains only the significant predictors. ${ }^{10}$

Starting with model 1 , we can see that most of the attribute variables do not have a statistical significant effect on tie emergence, that is, the likelihood of being chosen as a target for political information exchange. The coefficients of the attribute are always in the "in"-form, representing the likelihood that an actor with such an attribute receives a tie (an indegree measure). As hypothesized by the status/ information theory, being/having been a minister increases the likelihood of being chosen as discussion partner. All the other factors, however, have no direct effect on the network shape. Neither the electoral success, the status measured by age, the maturity measured by the number of legislative periods, nor our control variable gender show significant results.

Homophily was defined as the principle that a contact between similar actors occurs at a higher rate than among dissimilar actors (McPherson et al., 2001). In our case, we assumed that the likelihood of choosing another MP as partner for political discussion is higher when MPs share common attributes. We hypothesized parties as ideological structures that produce similarity in policy preferences to be one of the main factors for tie formation. However, model 2 delivers no empirical evidence for that driving factor in the Ghanaian parliament. Here, a political discussion between two members of the same party is not significantly different from a tie between two MPs of different parties. The political party therefore does not seem to be a major determinant for informal behavior.

Our two alternative explanations for informal political exchange between two MPs with similar attributes work better. First, we hypothesized that having the same ethnicity will increase patronage relationships between MPs and therefore the likelihood of asking for political advice. Model 3 shows a positive and weakly significant effect for that relationship. We based our second alternative explanation on similarity in region. Coming from the same region should foster informal relations due to local policy preferences. A desire for regional support is present for MPs from the same region independent from their party affiliation. Therefore, advice and information exchange should be more likely. Indeed, model 4 of our analysis supports this claim. We can see a strong positive and significant effect for regional homophily. 
To assess the robustness of our results, we come up with a final model 5 that includes only the significant effects. Whereas all the other variables keep their significance and the general model fit measured by the Bayesian information criterion (BIC) and Akaike information criterion (AIC) improves, ethnicity loses its explanatory power. When cross-checked with the somehow overlapping regional homophily, our results suggest that not the ethnic patronage mechanism is at work when it comes to tie formation, but that the similarity in regional policy preferences is the driving force behind information exchange of MPs in Ghana. Therefore, our main finding is that beyond all party and ethnic considerations, specific regional policy interests are the main factor that leads MPs in Ghana to discuss about political decisions with their fellow MPs.

The qualitative evidence presented in the theory section furthermore suggests that the shared attributes ethnicity and region should have a strong impact on political exchange within parties. We created an additional quasi-interaction effect to test if MPs who belong to the same party and the same ethnicity or the same party and the same region are more likely to exchange information. Surprisingly, as Table B1 in Appendix 1 shows, we find no significant effect for that stricter homophily assumption. Region and ethnicity influence MP behavior when taking into account all MPs, but not when looking only at partners from the same party.

For the whole political exchange process in the Ghanaian parliament, the last two rows of Table 1 demonstrate the general network nature. Therefore, the geometrically weighted edgewise shared partner distribution (GWESP) and the geometrically weighted dyad-wise shared partner distribution (GWDSP) are interpreted together (Hunter, 2007; Leifeld and Schneider, 2012). The GWESP statistic is positive and highly significant in all models, indicating that triadic effects are at work. This means that connected dyads are likely to have approximately one or two transitive shared partners, a general network effect. The GWDSP is significant and negative, that is, there are generally fewer unconnected dyads with shared partners than predicted by chance, another indication that the selection of political discussion partners follows general network logic. That our models are generally a good representation of the general political reality can additionally be seen in the supplementary material where we present the goodness of fit diagnostics.

\section{Conclusion}

Our article has intended to shed light on informal political exchange in Ghana. Using a social network approach, we have shown that regional homophily is the strongest predictor for tie formation. The results make a lot of sense in the context of resource allocation politics in Ghana. As André and Mesplé-Somps (2009) have shown, regional considerations play a role in the decisions about the allocation of infrastructure and development projects. MPs coming from the same region might therefore have a shared interest in attracting investments in their home region. This, in turn, provides an incentive to establish closer relations with regional peer. The fact that region outperforms ethnicity is an interesting finding which suggests that African politics is not solely driven by ethnic considerations. Future research should pay more attention to regional patterns of political action.

Party homophily, on the other hand, is not a strong predictor for informal exchange. This is somehow surprising because Ghana's parties are often described as relatively strong and well institutionalized (Basedau and Stroh, 2008: 19; Osei, 2012). It fits, however, into the general picture of African parties as unable to provide a common platform for shared ideologies and policy preferences. In this context, it is also interesting to note that shared ethnic or regional identities have no impact on political exchange within parties. This finding suggests that ethnicity and region build bridges between parties rather than creating conflict between them.

Another novel finding is the fact that acting or former ministers receive significantly more ties than other actors, whereas all other individual attributes have no effect. This points to new directions in future research because it suggests that interesting processes of exchange might also take place within political parties. The finding is perhaps not surprising because the literature on patron-client relationships in Africa (see, e.g. Chabal and Daloz, 2000) has argued that contacts to a "Big Man" are generally beneficial - for the access to information but also for the advancement of one's own career. Given the almost complete absence of research on party organization in Africa (see also, Carbone, 2007), our finding could perhaps inspire new research on informal networks within parties.

\section{Acknowledgements}

The authors want to thank the Center for Democratic Development (CDD) in Accra/Ghana for the generous assistance; special thanks go to Prof. Emmanuel Gyimah-Boadi, Franklin Oduor, Mohammed Awal, and Regina Oforiwaa-Amanfo. Furthermore, we thank Philip Leifeld and two anonymous reviewers for their helpful comments on an earlier version of the paper.

\section{Declaration of Conflicting Interests}

The author(s) declared no potential conflicts of interest with respect to the research, authorship, and/or publication of this article.

\section{Funding}

The author(s) received no financial support for the research, authorship, and/or publication of this article.

\section{Notes}

1. Interview with a Member of Parliament, October 10, 2012, Dunkwa, Central Region, Ghana. 
2. There might, however, also be negative consequences. High levels of horizontal elite integration widen the gap between political representatives and the electorate and bear the danger of producing an oligarchy (Putnam, 1976). Thus, a maximization of horizontal integration is detrimental to vertical integration, which is understood as the relationship between elected representatives and citizens. Strong vertical integration, on the other hand, makes elites more representative and accountable to their voters, but could hinder political compromises and block decision-making (ibid.).

3. Ghana Statistical Service (2013: 61).

4. In line with Müller (2000), we see Germany as representative case for West European parliamentary systems.

5. Nkrumah, Ghana's first president (1957-1964) stood for panAfricanism and socialism. A number of small Nkrumahist parties exist until today, for example, the People's National Convention and the Convention People's Party. Their vote shares have, however, significantly decreased over the past elections.

6. We thank George Ofosu, PhD student at the University of California Los Angeles for the clarification of this point.

7. The General Social Survey has been monitoring social change in the United States since 1972. For more on this, see http://www.norc.org/Research/Projects/Pages/generalsocial-survey.aspx. See Burt (1984) for more on network items in the survey.

8. The data set draws a further distinction between "Asante" and "other Akans." For this article, the decision to merge all Akan MPs into one group was mainly taken because the information on the subgroups was incomplete as some of the MPs identified themselves as Akan, whereas others referred to their subgroup identity such Asante, Fanti, and so on.

9. An alternative analytical approach would be latent space models (Hoff et al., 2002). Generally, they could be preferred if the analytical interest is in the main effects under control of the network dependencies. We prefer the exponential random graph models since they are based on theoretical specifications of the network dependencies, (Figure A1) whereas the latent space models relegate the dependencies to the latent social space (Cranmer et al., 2016).

10. For this model, we also attach the goodness of fit (Figure A1) and the sample statistics for the Markov Chain Monte Carlo (Figure B1) in the appendix.

\section{References}

Aguilar MI (2007) Rethinking Age in Africa: Colonial, Postcolonial, and Contemporary Interpretations of Cultural Representations. Trenton: Africa World Press.

André P and Mesplé-Somps S (2009) The Allocation of Public Goods and National Elections in Ghana. Paris: Mimeo, Paris School of Economics.

Aron R (1950) Social structure and the ruling class: Part 1. The British Journal of Sociology 1(1): 1-16.

Auel K and Benz A (2005) The politics of adaptation: The Europeanisation of national parliamentary systems. The Journal of Legislative Studies 11(3-4): 372-393.
Azevedo-Harman E (2012) Parliaments and citizens in SubSaharan Africa. Journal of Legislative Studies 18(3-4): 419440.

Bailer S (2014) Interviews and surveys in legislative research. In Martin S, Saalfeld T and Strøm KW (eds) The Oxford Handbook of Legislative Studies. Oxford: Oxford University Press, pp. 167-193.

Bailey S and Marsden PV (1999) Interpretation and interview context: examining the general social survey name generator using cognitive methods. Social Networks 21(3): 287309.

Barkan JD (2009) Legislative Power in Emerging African Democracies. Boulder: Lynne Rienner Publishers.

Basedau M, Erdmanna G, Lay J, et al. (2011) Ethnicity and party preference in Sub-Saharan Africa. Democratization 18(2): 462-489.

Basedau M and Stroh A (2008) Measuring party institutionalization in developing countries: a new research instrument applied to 28 African political parties. GIGA Working Paper No. 69. Hamburg: German Institute of Global and Area Studies.

Best H (2010) Associated rivals: antagonism and cooperation in the German political elite. In: Best H and Higley J (eds) Democratic Elitism: New Theoretical and Comparative Perspectives. Leiden and Boston: BRILL, pp. 97-116.

Boafo-Arthur K (2006) Introduction. In: Boafo-Arthur K (ed) Voting for Democracy in Ghana: The 2004 Elections in Perspective. Vols. 1 \& 2. Accra: Freedom Publications, pp. 1-14.

Bob-Milliar GM (2012) Party factions and power blocs in Ghana: a case study of power politics in the National Democratic Congress. The Journal of Modern African Studies 50(4): 573-601.

Burt RS (1984) Network items and the general social survey. Social Networks 6: 293-339.

Cederman L-E, Wimmer A and Min B (2010) Why do ethnic groups rebel? New data and analysis. World Politics 62(1): 87-119.

Carbone GM (2007) Political parties and party systems in Africa: themes and research perspectives. World Political Science Review 3(3): 1-29.

Chabal P and Daloz J-P (2000) Africa Works: Disorder as Political Instrument. Oxford: James Currey.

Conroy-Krutz J (2013) Information and ethnic politics in Africa. British Journal of Political Science 43(2): 345-373.

Cranmer SJ, Philip L, Scott D, et al. (2016) Navigating the Range of Statistical Tools for Inferential Network Analysis. American Journal of Political Science 61(1): 237-251.

Elischer S (2012) Measuring and comparing party ideology in nonindustrialized societies: taking party manifesto research to Africa. Democratization 19(4): 642-667.

Fowler JH (2006) Connecting the congress: a study of cosponsorship networks. Political Analysis 14(4): 456-487.

Fridy KS (2007) The elephant, umbrella, and quarrelling cocks: disaggregating partisanship in Ghana's fourth republic. African Affairs 106(423): 281-305. 
Ghana Statistical Service (2013) 2010 Population \& Housing Census. National Analytical Report. Accra: Ghana Statistical Service.

Handcock MS, Hunter DR, Butts CT, et al. (2008) Statnet: software tools for the representation, visualization, analysis and simulation of network data. Journal of Statistical Software 24(1): 1548 .

Higley J and Burton M (2006) Elite Foundations of Liberal Democracy. Lanham: Rowman \& Littlefield.

Higley J, Hoffmann-Lange U, Kadushin C, et al. (1991) Elite integration in stable democracies: a reconsideration. European Sociological Review 7(1): 35-53.

Hoff PD, Raftery AE, Handcock MS, et al. (2002) Latent space approaches to social network analysis. Journal of the American Statistical Association 97(460): 1090-1098.

Horowitz DL (1985) Ethnic Groups in Conflict. Berkeley and Los Angeles: University of California Press.

Hunter DR (2007) Curved exponential family models for social networks. Social Networks 29(2): 216-230.

Hunter DR, Handcock MS, Butts CT, et al. (2008) ergm: A package to fit, simulate and diagnose exponential-family models for networks. Journal of Statistical Software 24(3).

Jonah K (1998) Political parties and the transition to multi-party politics in Ghana. In: Ninsin KA (ed) Ghana - Transition to Democracy, pp. 83-107. Dakar: CODESRIA.

Kopecký P (1996) Parties in the Czech parliament: from transformative towards arena type of legislature1996. In: Lewis PG (ed) Party Structure and Organization in EastCentral Europe. Cheltenhall: Edward Elgar Publishing, pp. 66-88.

Leifeld P and Volker S (2012) Information Exchange in Policy Networks. American Journal of Political Science 53(3): 731744.

Lindberg SI (2009) Member of the parliament of Ghana: a hybrid institution with mixed effects. Working Paper No. 2. Overseas Development Institute, London: African Power and Politics Research Program.

Lindberg SI (2010) Variation in performance among members of parliament: evidence from Ghana. Working Paper No. 7. Overseas Development Institute, London: African Power and Politics Research Program.

Lindberg SI and Morrison MKC (2005) Exploring voter alignments in Africa: core and swing voters in Ghana. The Journal of Modern African Studies 43(4): 565-586.

McClurg SD and Lazer D (2014) Political Networks. Social Networks 36: 1-4.

McPherson M, Lynn S-L and Cook JM (2001) Birds of a feather: homophily in social networks. Annual Review of Sociology 27(1): 415-444.

Mozaffar S and Scarritt JR (2005) The puzzle of African party systems. Party Politics 11(4): 399-421.
Müller WC (2000) Political parties in parliamentary democracies: making delegation and accountability work. European Journal of Political Research 37(3): 309-333.

Obeng-Odoom F (2013) The nature of ideology in Ghana's 2012 elections. Journal of African Elections 12(2): 75-95.

Osei A (2016) Formal Party organisation and informal relations in African parties: evidence from Ghana. The Journal of Modern African Studies 54(1): 37-66.

Osei A (2015) Elites and democracy in Ghana: a social network approach. African Affairs 114(457): 529-554.

Osei A (2012) Party-voter linkage in Africa: Ghana and Senegal in comparative perspective. Wiesbaden: VS Verlag für Sozialwissenschaften.

Owusu-Mensah I (2014) Parliamentary caucuses in Ghana's fourth republic: challenges and recommendations. Journal of Scientific Research and Reports 5(3): 252-264.

Posner DN (2005) Institutions and Ethnic Politics in Africa. New York: Cambridge University Press.

Putnam RD (1976) The Comparative Study of Political Elites. Englewood Cliffs: Prentice-Hall.

Rauschenbach M (2015) The importance of preaching to the converted: the strategic use of campaign rallies, campaign promises, clientelism, and violence in African elections. Available at: https://ub-madoc.bib.uni-mannheim.de/39000 (accessed 9 December 2015).

Robins G, Pattison P, Kalish Y, et al. (2007) An introduction to exponential random graph (p*) models for social networks. Social Networks 29(2): 173-191.

Whitfield L (2009) "Change for a better Ghana": party competition, institutionalization and alternation in Ghana's 2008 elections. African Affairs 108(433): 621-641.

Wonka A and Rittberger B (2014) The ties that bind? Intra-party information exchanges of German MPs in EU multi-level politics. West European Politics 37(3): 624-643.

Wucherpfennig J, Weidmann N, Girardin L, et al. (2011) Politically relevant ethnic groups across space and time: introducing the GeoEPR dataset. Conflict Management and Peace Science 28(5): 423-437.

Young DJ (2014) An initial look into party switching in Africa: evidence from Malawi. Party Politics 20(1): 105-115.

\section{Author biographies}

Anja Osei is a senior research fellow at the University of Konstanz, Chair of International Politics and Conflict Management. Her research focuses on parties and parliaments in Africa, democratization, and elite studies.

Thomas Malang is a senior researcher at the Chair of International Politics and Conflict Management. His research areas encompass national legislatures, European integration, and network analysis. 


\section{Appendix I}

Table Al. Regional distribution of seats in the 2012 parliamentary election.

\begin{tabular}{lrrcc}
\hline & NDC & NPP & PNC & Independent \\
\hline Ashanti & 3 & 43 & 0 & 0 \\
Brong-Ahafo & 16 & 13 & 0 & 0 \\
Central Region & 16 & 7 & 0 & 0 \\
Eastern Region & 7 & 26 & 0 & 0 \\
Greater Accra & 20 & 14 & 0 & 0 \\
Northern Region & 20 & 10 & 0 & 1 \\
Upper East & 12 & 2 & 1 & 0 \\
Upper West & 10 & 0 & 0 & 1 \\
Volta Region & 25 & 0 & 0 & 1 \\
Western Region & 18 & 8 & 0 & 0 \\
\hline
\end{tabular}

Note: NDC: National Democratic Congress; PNC: People's National Convention.

Source: Electoral Commission, 2012.
Table B I. ERGM of informal political cooperation: Interactions.

\begin{tabular}{lrr}
\hline & $(1)$ & \multicolumn{1}{c}{$(2)$} \\
\hline Edges & $-2.42^{* * *}(0.15)$ & $-2.37^{* * *}(0.16)$ \\
Reciprocity & $1.16^{* * *}(0.21)$ & $1.16^{* * *}(0.16)$ \\
Minister & $0.35^{* * *}(0.06)$ & $0.35^{* * *}(0.06)$ \\
Party + ethnic homophily & $0.13(0.09)$ & \\
Party + regional homophily & & $0.19(0.11)$ \\
GWESP =0 & $1.32^{* * *}(0.07)$ & $1.30^{* * *}(0.07)$ \\
GWDSP =0 & $-0.22^{* * *}(0.02)$ & $-0.23^{* * *}(0.02)$ \\
AIC & -1799 & -1802 \\
BIC & -1744 & -1746 \\
Log likelihood & 905.58 & 906.76
\end{tabular}

Note: ERGM: exponential random graph model; GWESP: geometrically weighted edgewise shared partner distribution; GWDSP: geometrically weighted dyad-wise shared partner distribution.

$*_{* *}<<0.01 ; * * p<0.05 ; *_{p}<0.1$.

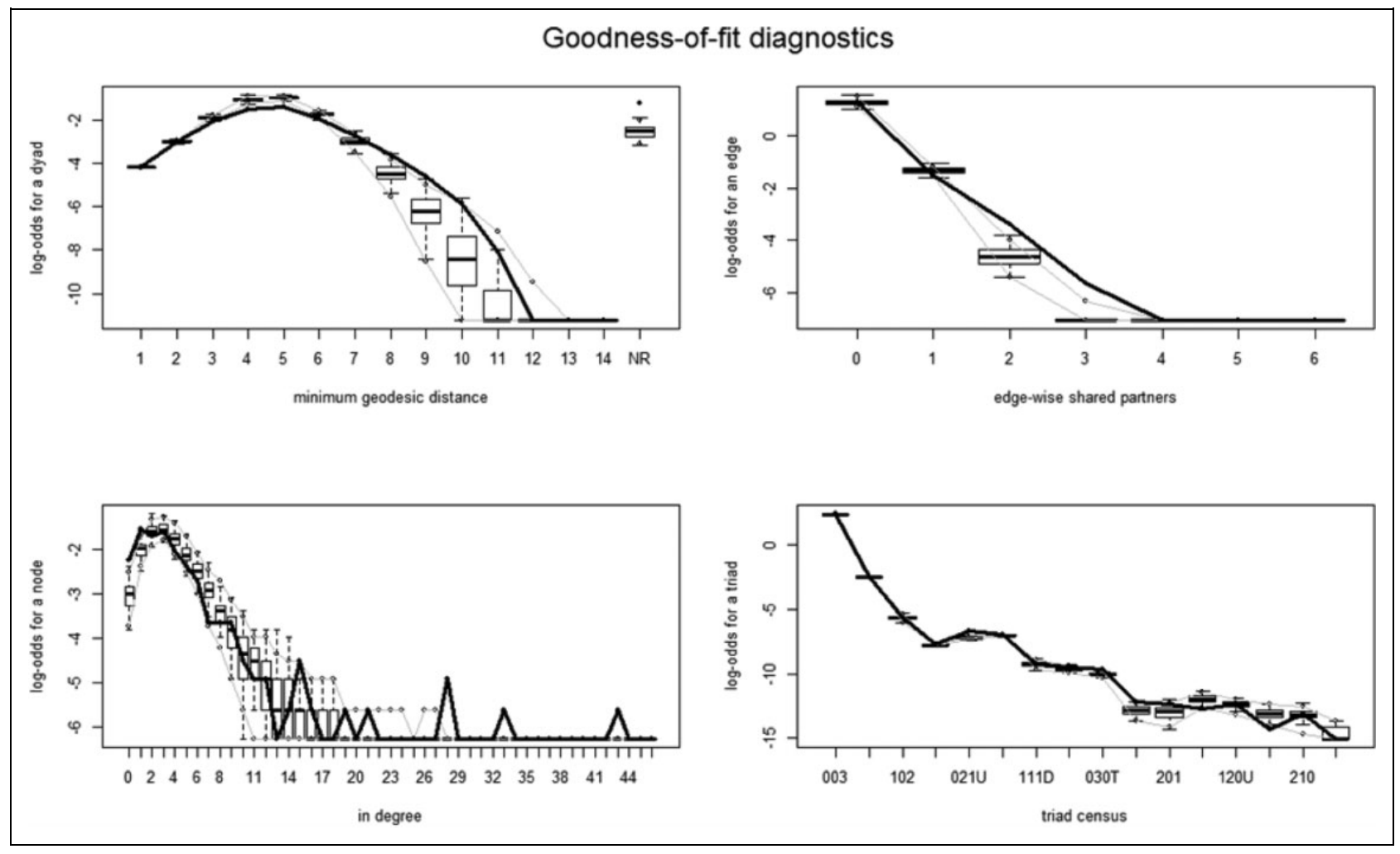

Figure Al. Goodness-of-fit diagnostics for model 5.

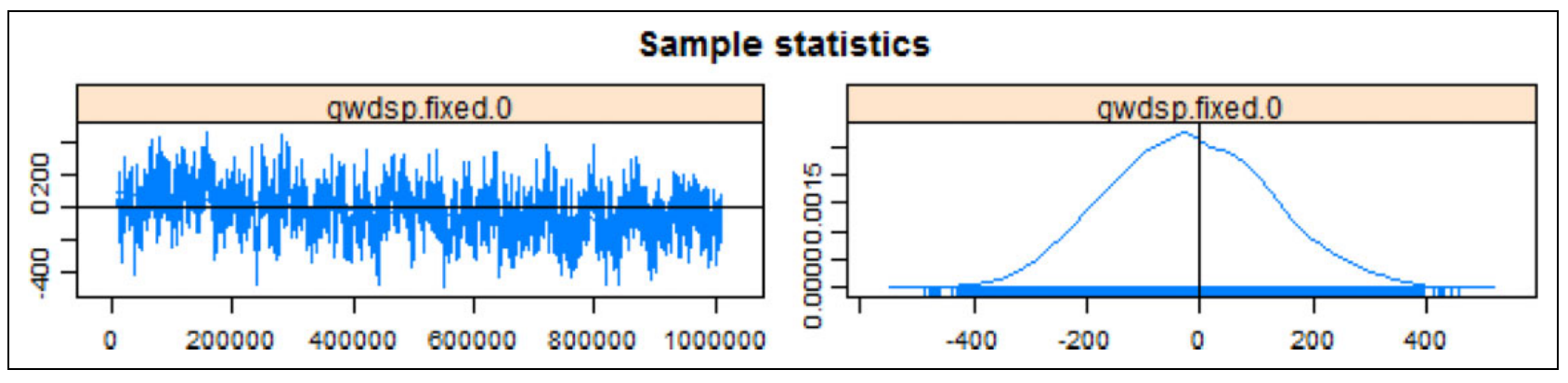

Figure B I. Sample statistics for the Markov Chain Monte Carlo simulation. 